Laboratorio de Arte,4-1991 http://dx.doi.org/10.12795/LA.1991.i04.19

\title{
UNA IMAGEN DE JESÚS ORANTE EN EL GÓLGOTA DE LOS HERMANOS GARCÍA EN SEVILLA
}

\author{
por JuAN CarRero RodríGuez
}

Coincidiendo con la apertura del Concilio de Trento, en 1545, el venerable Pedro Pecador fundaría en Sevilla el convento de Ntra. Sra. de la Paz en el sitio donde actualmente se encuentra el Archivo de Indias. En dicho emplazamiento permanece la congregación oriunda granadina, hasta que en 1574 (dos años después de que Pío V aprobara la institución hospitalaria, concediéndoles gracias e indulgencias) se trasladara a la plaza del Divino Salvador, donde se iniciaría el espíritu de la hospitalidad, de asistir a los enfermos pobres, creada por San Juan de Dios.

\section{Imagen de Jesús orante}

Tras las restauraciones que se han efectuado a la fábrica de este convento, en nuestros días, le ha tocado igualmente realizarla sobre una imagen de dicho lugar, ejecutada en terracota. Representa iconológicamente el momento en que Cristo se encuentra orando, antes de su Crucifixión.

Un busto prolongado, cortado horizontalmente a la altura de la cadera. La divina testa presenta un leve giro hacia la izquierda y mirada en alto; rostro de correctas facciones, con la boca entreabierta. La corona de espinas entrelazadas con los bucles del cabello, de estriado sinuoso y profundo, una espina atraviesa la ceja. Parece ensimismado, reconcentrado y dulce a la vez. 
Muestra un cuerpo anatómico con fuerte musculatura, entumecido de dolor. El sufrimiento ha cubierto la piel de morados y lluvia de sangre de crueles martirios, llenando de dramatismo su figura. El tipo de la encarnación es mate. Una gruesa soga ciñe el cuello y ata sus manos entrelazadas en oración. El paño de pureza con moña atada al siniestro. Mide 0,91 metros.

El trabajo de restauración de esta efigie lo ha efectuado el frexnense Manuel Carmona Martínez (1938), limpiando la carnación de manera superficial sin llegar a la pátina, que conserva la original. Manifestaba la escultura numerosos desportillados por causa de la higrometría, siendo saneados a punta de pincel para igualarlo con el resto de la policromía que tiene. También ha recompuesto las espinas de plomo que faltaban a la corona.

Se desconoce cuándo llegó la imagen al convento hospitalario, como así la autoría de quien la creara. Estudiada, encaja totalmente con la obra de los granadinos hermanos García, que parte del descubrimiento del conde de Maule, cimentada por las atribuciones posteriores, no sólo justificadas por el parecido, sino agregado a la materia con que principalmente trabajaron estos artistas, el barro y las características artísticas, anatomía, cabello y sudario de elegantísimos pliegues barroquizantes.

\section{Los hermanos García}

A últimos del XVI y principios del XVII, en Granada, se vivía un período de gran raigambre artística, por las obras que se habían consolidado tras la reconquista de la ciudad, en construcciones de grandes templos y palacios, acercando a su entorno notabilísimos escultores que crearon una escuela de gran personalidad.

Entre estos imagineros hay que destacar principalmente en este período a Pablo de Rojas, activo entre 1581-1607, cuya localización de su nacimiento en Alcalá la Real (Jaén) en 1549, ha sido encontrada en 1984 por el investigador Francisco Martín González, en cuyo taller trabajaría en su labor de aprendizaje nuestro inmortal Juan Martínez Montañés (1568-1649). También laboraba entonces Alonso de Mena (1587-1646) y coincidente con ellos los hermanos gemelos Jerónimo Francisco y Miguel Jerónimo García, más bien conocidos como los hermanos García. Se desconoce cuándo nacerían, y sólo existen mencionados en un libro escrito en Granada al comenzar el siglo XVII por el analista Francisco Bermúdez de Pedraza, editado en Madrid en 1608, "Antigüedades y Excelencias de Granada", donde exponía: "dos hermanos de un parto", "los mayores estatuarios de cuerpo de zera que ay en Europa", resaltando que "no ay estrangero de ninguna nación que no les reconozca superioridad".

Antonio Acisclo Palomino en su "Vida de los pintores y estatuarios eminen- 
tes españoles" (1714-1724) referente a estos hermanos García se hace eco del texto de Bermúdez de Pedraza, ampliándolo con otro poético de Pedro Araujo Salgado, en el que hace distinción "ambos se inclinaron a la pintura y escultura", añadiendo "el uno era eminente, o se señalaba más en hazer las efigies de bulto, y el otro en colorearlas o pintarlas". De su obra sólo comentaba que se encontraba en la región de Granada.

Ceán Bermúdez, en su "Diccionario histórico de los más ilustres profesores de las Bellas Artes en España" (1800), indica que habían sido canónigos de la colegiata del Salvador, del barrio del Albaicín granadino.

El conde de Maule, en su "Viaje de España, Francia e Italia" tomo XII, es el primero en publicar una obra de dichos hermanos, referente a la iglesia granadina de San Justo y Pastor, aunque no aclaraba a cual se refería, ya que en dicho templo se atesoran dos de ellas, un busto representativo de Jesús orante antes de su Crucifixión y un relieve del Ecce-Homo.

Coincidente con el cordobés Juan de Mesa y Velasco (1583-1627), la obra de los hermanos García se encontraba diluida y poco se sabía de ella, aún con la importancia en la técnica magistral que imprimían en su trabajo, sobre todo en el tratamiento del desnudo. Estimo que fueron los primeros en barroquizar en Andalucía el paño de pureza, continuada con Alonso de Mena, Montañés, Juan de Mesa, hasta llegar al último, Francisco Antonio Gijón.

Es a partir de 1934, cuando aparece un pequeño librito monográfico referente a estos artistas, realizado por el investigador Emilio Orozco Díaz "Los hermanos García" (Escultores del Ecce-Homo).

Según Manuel Gómez Moreno, la formación de estos escultores debió verificarse en Sevilla, ya que era el sitio donde el empleo del barro como material casi exclusivo se usaba entre lo catalogado de Lorenzo Mercadante, Pedro Millán, Miguel Perrín o Torrijiano. Que pudieran haber conocido los granadinos a Gaspar Núñez, activo en Sevilla entre 1581 a 1606, especialista en la terracota, teniendo entre sus obras en la colección de Gómez Moreno, en Madrid, un EcceHomo, a la manera de figura cortada, muy al uso en la región granadina.

Por afinidad con los de la iglesia de San Justo y Pastor, Orozco y Díaz incluye en la obra de estos hermanos el genial barro de la Cartuja de Granada, que se tenía hasta entonces ligado al arte italiano. Asimismo aporta en su estudio un grupo de numerosas obras, todas realizadas en terracota.

\section{El Crucificado de la Catedral de Granada}

Es en el año 1940 cuando se produce la catalogación a estos artistas de un bellísimo Crucificado que se mantenía como obra del alcalaíno Martínez Montañés por su semejanza con el sevillano de la Clemencia. Orozco lo clasifica, por 
comparación con el orante de la Cartuja, con la variante de la encarnadura al habérsele imprimido en el siglo XVIII y la diferenciación de su materia, la madera. Sobresalen muchas singularidades de los García, la anatomía, expresión del rostro, y añado los ensortijados bucles en la corona de espinas.

Cuando en Madrid, en el Casón del Buen Retiro, en los meses de mayo-junio de 1969, se instaló la exposición "Martínez Montañés y la escultura andaluza de su tiempo", figuró este Crucificado en el catálogo como obra de los hermanos García, realizado hacia 1600 , mide 1,85 metros.

Otra imagen con analogía al de la Catedral granadina es la sevillana concertada en 1611 por el jiennense Francisco de Ocampo Felguera (1579-1639) para Gaspar Pérez de Torquemada y actualmente titular de la cofradía del Calvario. Aparece muerto con los ojos cerrados y de igual contextura anatómica. Los pies, con un solo clavo, mientras que los de la Clemencia sigue las orientaciones de los cuatro clavos de las revelaciones de Santa Brígida. El paño de pureza guarda más relación con este último, mide 1,77 metros.

\section{Los Ecce-Homo}

Díaz Orozco, en el librito citado, define a los hermanos García como los escultores del Ecce-Homo, refiriéndose a la mayor parte de su producción cristífera. Quien aporta este trabajo no está de acuerdo con esta definición, ya que se trata de parte de su obra como representación iconológica del momento de ser presentado Jesús en el pretorio, en que tras haber hecho Pilato azotarlo, los soldados lo conducen al litóstrotos, y desnudándolo de sus vestiduras, le echaron encima una clámide de púrpura, y tejiendo una corona de espinas, se la pusieron sobre la cabeza, y en la mano una caña como burla, diciendo: "¡Salve, Rey de los Judíos!".

En Valladolid, en el Museo Diocesano y procedente de la parroquia de Villanueva de Duero, existe un Ecce-Homo que ejecutara el borgoñés Juan de Juni (1507-1577), de busto, cortado horizontalmente, sin brazos, recordando la producción italianizante, y puede decirse que es primigenia en su introducción en el arte español. Lleva corona de espinas en el mismo bloque de la madera, trenzándose con las ondulaciones del cabello, cuyos mechones están separados de modo bulboso. Lleva clámide, ofreciendo a la vista el pectoral a modo romano.

Los que estilísticamente se inscriben de los García en la anterior descripción son los realizados a modo de relieve, en barro, apareciendo sobre los hombros la clámide de púrpura y en las manos la caña por cetro: Los de la Santa Caridad, de Sevilla, de 0,60 x 0,47 metros. Templo granadino de San Justo y Pastor, de 0,38 metros, y conventos de Santa Inés y el de los Angeles (ambos estilísticamente muy parecidos) y solo llevando la púrpura: el de busto (pequeño) del convento 
del Angel y el de San Antonio Abad. El de la colección Roda, de Madrid, circunscrito como el de la Caridad, de Sevilla, en un molduraje poligonal. El de la iglesia de San Bartolomé, de Jaén, y el de San Francisco, de Priego de Córdoba.

\section{Jesús orante en el Gólgota}

Otro tipo y tema principal con el que relaciono la nueva obra aparecida en Sevilla es la de Jesús de rodillas, desnudo en el Gólgota, esperando su Crucifixión, interpretado con las manos extendidas en súplica, o entrelazadas implorantes. No existe alusión alguna de este pasaje en los evangelios.

En la obra de los García encontramos en el convento de Santa Isabel la Real, de Granada, uno genuflexo, con los brazos extendidos, de 0,20 metros, y el de igual forma de las capuchinas de San Antonio Abad, con las manos entrelazadas, de 0,15 metros.

En cuanto a los cortados horizontalmente, en Granada, el más importante es el de la Cartuja, que lo está a la altura de las rodillas, de 1,75 metros. Es el de mayor movimiento, con el torso echado hacia adelante y las manos entrelazadas en oración. Los del convento del Angel e iglesia de San Justo y Pastor parecen corresponder a un mismo modelo, solo con las variantes de la soga y paño de pureza. De menor tamaño, 0,22 metros, es el del convento de Santo Domingo, y circunscrito a él clasifico el existente en el Museo de la Catedral de Cádiz.

A este tipo iconológico hay que incluir el que encasillo su autoría a los García, del convento de Ntra. Sra. de la Paz, de la orden hospitalaria de San Juan de Dios, de Sevilla, y que coincide al de medio cuerpo del granadino de San Justo y Pastor, por lo que puede ser una repetición de barro sacada de un mismo molde.

\section{El modelo en España}

Contada es la producción que existe en España referente a este tema, de entre ellos, en Valladolid, el del Museo Catedralicio, procedente del convento de Trinitarios Descalzos, en la advocación del Perdón, obra atribuida a Francisco Díez de Tudanca. Este modelo sería repetido en 1664 por dicho escultor y con destino a Pamplona, con alusión de imitar al vallisoletano. En dicha ciudad castellana, en la iglesia de la Magdalena, otro del mismo asunto, desconociéndose quién lo labrara, siglo XVII.

El portugués Manuel Pereira (1588-1683) trasladaría en la madera este tipo, para los dominicos del Rosario, de Madrid, perdido en 1936, quedando una réplica en el oratorio de los marqueses de Comilla, en su ciudad. 
Dicho trasunto también se encuentra en Sevilla, en el templo de la Santa Caridad, en un retablo del lado de la Epístola, de 1,25 metros, cuya labra en 1674 pertenece al sevillano Pedro Roldán (1624-1699), quien cobraría 18.700 reales, interpretando la idea de Mañara, que fue quien lo encargó.

La escultura sevillana se enriquece en su enorme catalogación de imagineros con esta obra del convento de Ntra. Sra. de la Paz, que viene a sumar al relieve del Ecce-Homo de la iglesia de la Caridad, creados ambos por los hermanos García. 


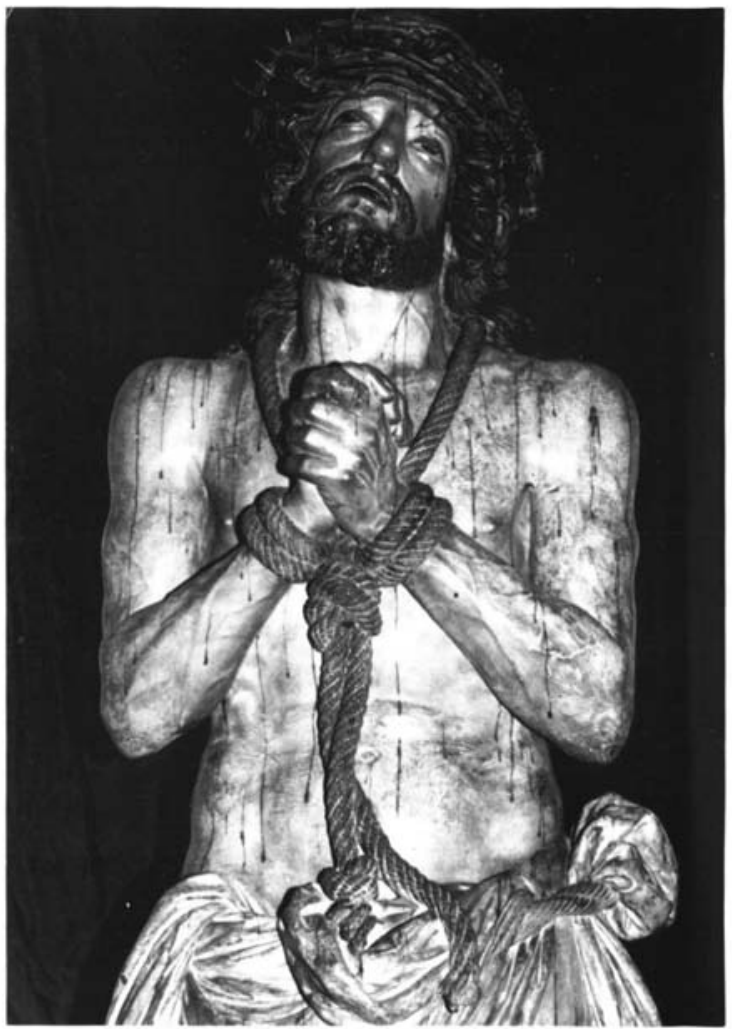




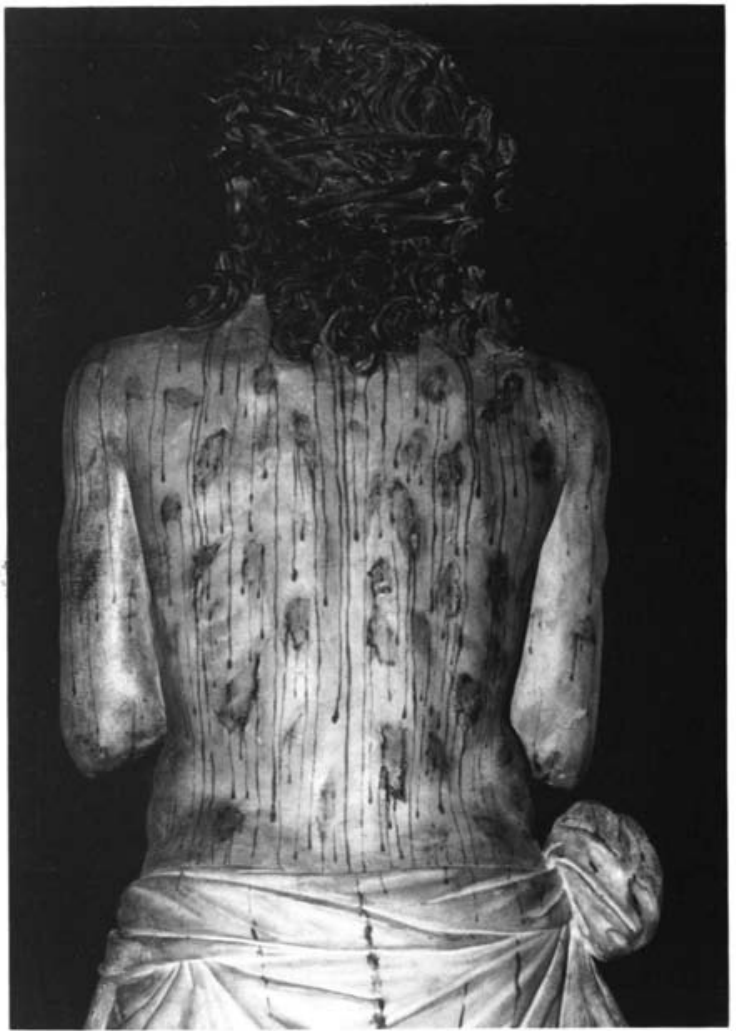

